\title{
Etnoconhecimento dos apicultores de um município do semiárido potiguar, Nordeste do Brasil
}

\author{
Carlos Piffero Câmara ${ }^{1}$ (D), Rayane de Tasso Moreira Ribeiro² ${ }^{(D)}$, Maria Iracema Bezerra Loiola ${ }^{3}$ (D) \\ 1 Universidade Federal do Ceará, Av. da Universidade, 2853 - Benfica, Fortaleza - CE, 60020-181. \\ 2 Universidade Federal Rural de Pernambuco, Dois Irmãos, Recife - PE, 52171900. \\ 3 Universidade Federal do Ceará, Centro de Ciências, Departamento de Biologia, Herbário Prisco Bezerra, Campus da \\ UFC, Pici, Fortaleza - CE, 60440900. \\ * Autor para correspondência: iloiola@ufc.br
}

Recebido em 14 de janeiro de 2021.

Aceito em 12 de abril de 2021.

Publicado em 15 de abril de 2021.

Resumo - Objetivou-se registrar o etnoconhecimento dos apicultores em relação aos recursos florestais e os impactos das mudanças climáticas sobre a flora do município de Marcelino Vieira, Rio Grande do Norte. As ações da pesquisa ocorreram no período de março a julho/2018 e contou com a participação de 20 apicultores selecionados por meio de amostragem não-probabilística a partir dos dados da Associação Comunitária Jefferson Fernandes de Medeiros. Para a obtenção dos dados utilizou-se de observação participante, listas livres, turnês-guiadas, diário de campo e aplicação de formulário estruturado. $\mathrm{O}$ uso das plantas foi classificado conforme descritores pré-estabelecidos. Constatou-se que os apicultores fazem uso de 68 espécies vegetais agrupadas em cinco descritores: alimentar, madeireiro, medicinal, combustível e forragem. A maioria das espécies (54) tem utilidade medicinal, com destaque para Anacardium occidentale L./ Cajueiro $(0,45)$ e Astronium urundeuva (M.Allemão) Engl./ Aroeira $(0,4)$ que apresentaram os maiores valores de uso (VU). A maioria dos apicultores (85\%) acreditam que as temperaturas mais elevadas e escassez de chuvas estão associadas com a redução das áreas florestais no município. Conclui-se que os apicultores detêm importante conhecimento sobre os recursos naturais manejados, e devem ser valorizados para a implementação de ações de sustentabilidade da Caatinga no Alto-Oeste Potiguar.

Palavras-chave: Caatinga. Plantas úteis. Recursos florestais. Sabedoria popular.

\section{Ethno-knowledge of beekeepers in a municipality in the semiarid potiguar, Northeastern Brazil}

Abstract - The aimed to record beekeepers' ethno-knowledge about forest resources and the impacts
of climate change on the flora of the municipality of Marcelino Vieira, Rio Grande do Norte. The
research actions took place from March to July/2018 and included the participation of 20 beekeepers
selected through non-probabilistic sampling based on data from the Jefferson Fernandes de Medeiros
Community Association. To obtain the data, the techniques used were participant observation,
free lists, guided tours, field diary and application of a structured form. The use of plants was
classified according to pre-established descriptors. Beekeepers were found to make use of 68 plant
species grouped into five descriptors: food, timber, medicinal, fuel, and forage. Most species (54)
have medicinal uses, with emphasis on Anacardium occidentale L./ Cajueiro (0,45) and Astronium
urundeuva (M.Allemão) Engl./ Aroeira $(0,4)$ that presented the highest use value (VU). The majority 
of beekeepers (85\%) believe that higher temperatures and scarcity of rainfall are associated with the reduction of forest areas in the municipality. It's concluded that beekeepers have important knowledge about the natural resources managed, and should be valued for the implementation of sustainability actions in the Caatinga in the Potiguar High-West.

Keywords: Caatinga. Useful plants. Forest resources. Popular knowledge.

\section{Etnocognición de apicultores de un municipio de la región semiárida potiguar, Nordeste de Brasil}

Resumen - El objetivo fue registrar el etnoconocimiento de los apicultores sobre recursos forestales y los impactos del cambio climático en la flora del municipio de Marcelino Vieira, Rio Grande do Norte. Las acciones de investigación se llevaron a cabo de marzo a julio/2018 y contaron con la participación de 20 apicultores seleccionados mediante muestreo no probabilístico con base en datos de la Asociación Comunitaria Jefferson Fernandes de Medeiros. Para la obtención de los datos se utilizó la observación participante, listas libres, visitas guiadas, diario de campo y aplicación de un formulario estructurado. El uso de plantas se clasificó según descriptores preestablecidos. Se descubrió que los apicultores utilizan 68 especies de plantas agrupadas en cinco descriptores: alimento, madera, medicinales, combustible y forraje. La mayoría de las especies (54) tienen usos medicinales, con énfasis en Anacardium occidentale L./ Cajueiro (0.45) y Astronium urundeuva (M.Allemão) Engl./ Aroeira $(0,4)$ que presentaron el mayor valor de uso (VU). La mayoría de los apicultores $(85 \%)$ cree que las temperaturas más altas y la escasez de lluvias están asociadas con la reducción de las áreas forestales en el municipio. Se concluye que los apicultores tienen un conocimiento importante sobre los recursos naturales manejados, y deben ser valorados para la implementación de acciones de sustentabilidad en la Caatinga en el Alto Oeste potiguar.

Palabras clave: Caatinga. Plantas útiles. Recursos forestales. Sabiduría popular.

\section{Introdução}

A Caatinga, região semiárida do Brasil, é o núcleo de uma área florestal denominada "floresta tropical sazonalmente seca" (Castanho et al. 2020; Fernandes et al. 2020). Apesar da importância dessa formação vegetacional, considerada um dos maiores e mais importantes ecossistemas brasileiros, a região vem sofrendo sucessivas perdas de área nativa e grande parte de seus recursos vegetais estão desaparecendo drástica ou permanentemente (Bessa e Medeiros 2011; Brasil e BrasilGuimarães 2018).

Para a Caatinga são reconhecidas 153 famílias, 962 gêneros e 3.347 espécies de plantas, dessas 526 são exclusivas da região (Fernandes et al. 2020). Os números mencionados evidenciam a riqueza desse ecossistema. Além disso, muitas espécies representam fonte de recursos básicos para as populações residentes no semiárido brasileiro, como: alimentação, remédios, forragem para os mais variados tipos de rebanhos, madeira para construções, entre outros (Giulietti et al. 2003; Queiroz 2009). A flora da Caatinga contribui, portanto, consideravelmente para a melhoria da qualidade de vida dos residentes na região.

A diversidade cultural regional dos pequenos agricultores reflete-se na utilização de um número significativo de espécies vegetais de interesse econômico (Giannini et al. 2017). Ressaltase, ainda, que muitas dessas plantas são cultivadas localmente e contribuem para o incremento da 
renda familiar e qualidade de vida de pessoas em diferentes regiões do país. Apesar do interesse das pessoas em plantas economicamente relevantes, o processo de modernização do uso da terra e o crescimento de centros urbanos periféricos intensifica a desconstrução das redes de transmissão do conhecimento sobre plantas nas zonas rurais (Roque et al. 2010). Esse fato, enseja e justifica a necessidade de identificação de informações sobre o conhecimento etnobotânico com o intuito de preservá-las e repassá-las para as gerações futuras.

A perda de etnoconhecimentos, bem como a atual crise ambiental que o mundo enfrenta com as mudanças climáticas têm gerado incertezas e cenários inesperados e obscuros para o futuro da humanidade (Rovedder et al. 2016; Rito et al. 2017). A intensificação dos efeitos das mudanças climáticas representam uma série de consequências nas relações sociais, nos níveis populacionais, no estoque de alimentos, surgimento de novas doenças e maior incidência das existentes, além dos deslocamentos ambientais (Blank 2015). Outro desdobramento preocupante causado pelas alterações climáticas, é a perda de biodiversidade ocasionando declínio de animais polinizadores que são importantes a inúmeras culturas vegetais e, desempenham importantes serviços ecossistêmicos para animais e pessoas (Garófalo 2013; Azevedo 2016; Wolowski et al. 2019).

Um dos mais importantes polos apícola do semiárido potiguar está localizado no município de Marcelino Vieira, no estado do Rio Grande do Norte (RN). A apicultura no referido município é organizada por meio da Associação Comunitária Jefferson Fernandes de Medeiros, da qual são vinculados todos os apicultores da região. Os associados, em conjunto, desenvolvem práticas que relacionam a criação de polinizadores da espécie Apis mellifera Linnaeus, 1758 (Abelha-europeia), associando-as a utilização dos recursos ofertados pela flora local. Essa interação mostra-se extremamente necessária para assegurar a viabilidade econômica dessa atividade. Além disso, esses apicultores experientes podem ser identificados como potenciais informantes sobre as espécies vegetais existentes no local (Aleixo et al. 2014; Costa et al. 2018).

No contexto desse panorama, é portanto, de extrema relevância desenvolver estudos mais aprofundados focando a percepção dos atores sociais locais e as práticas relacionadas à utilização e conservação da flora associada às atividades apícolas. Tendo em vista que os apicultores se utilizam dos recursos vegetais para atender várias de suas necessidades de sobrevivência e para o desenvolvimento de suas diversas atividades, este estudo pretende responder as seguintes questões:

Quais são as espécies e para que finalidade os apicultores se utilizam da flora local?; Os apicultores conseguem identificar e distinguir as diferentes espécies vegetais?; Os apicultores conseguem identificar indicadores de mudanças climáticas e como essas alterações são percebidas durante o seu cotidiano?

Delineadas as problemáticas, formularam-se as seguintes hipóteses: H1- A assiduidade ao campo e as práticas apícolas permitem que os apicultores identifiquem e reconheçam os diferentes tipos de espécies vegetais que compõem a flora local; $\mathrm{H} 2$ - As práticas culturais favorecem o uso de plantas locais para as mais diversas finalidades e H3 - Os efeitos das mudanças climáticas são percebidos pelos apicultores durante a trajetória do exercício de suas atividades.

Diante do exposto e considerando que a atividade apícola vem sendo desenvolvida há quase três décadas nesta região do estado do Rio Grande do Norte, com considerável acúmulo de informações sobre a flora local, objetivou-se registrar o etnoconhecimento dos apicultores em relação aos recursos florestais e os impactos das mudanças climáticas sobre a flora do município de Marcelino Vieira, Rio Grande do Norte, região Nordeste do Brasil. 


\section{Material e métodos}

\section{Delimitação e caracterização da área de estudo}

O presente estudo foi realizado no município de Marcelino Vieira ( $\left.6^{\circ} 17^{\prime} 38,4^{\prime \prime} \mathrm{S}, 38^{\circ} 10^{\prime} 01,2^{\prime \prime} \mathrm{O}\right)$, estado do Rio Grande do Norte, região Nordeste do Brasil (Figura 1). Ocupa uma área de 345,711 $\mathrm{km}^{2}$ e apresenta população estimada de 8.265 habitantes, conforme Censo de 2010 (IBGE 2016). O município faz limite com diversos outros municípios: a norte com Pau dos Ferros, ao sul com Tenente Ananias, a leste com Pilões, Antônio Martins e Alexandria e a oeste com os municípios de José da Penha e Rafael Fernandes (Beltrão et al. 2005).

O clima do município é do tipo Semiárido quente (BSh), de acordo com a classificação de Köppen-Geiger, com temperatura média anual de $26,5^{\circ} \mathrm{C}$ e precipitação média de $843 \mathrm{~mm}$ anuais, com chuvas concentradas entre os meses de fevereiro e maio (CLIMATE-DATA 2021). A umidade relativa do ar é de $66 \%$ e o tempo de insolação chega a 2.700 horas anuais (IDEMA 2008). A cobertura vegetal é constituída por Caatinga hiperxerófila (30\%) e hipoxerófila (28\%), com alto percentual de vegetação em recuperação (23\%) e solo exposto (16\%) (Da Silva et al. 2020).

Figura 1. Mapa de localização do município de Marcelino Vieira - RN, Nordeste do Brasil.

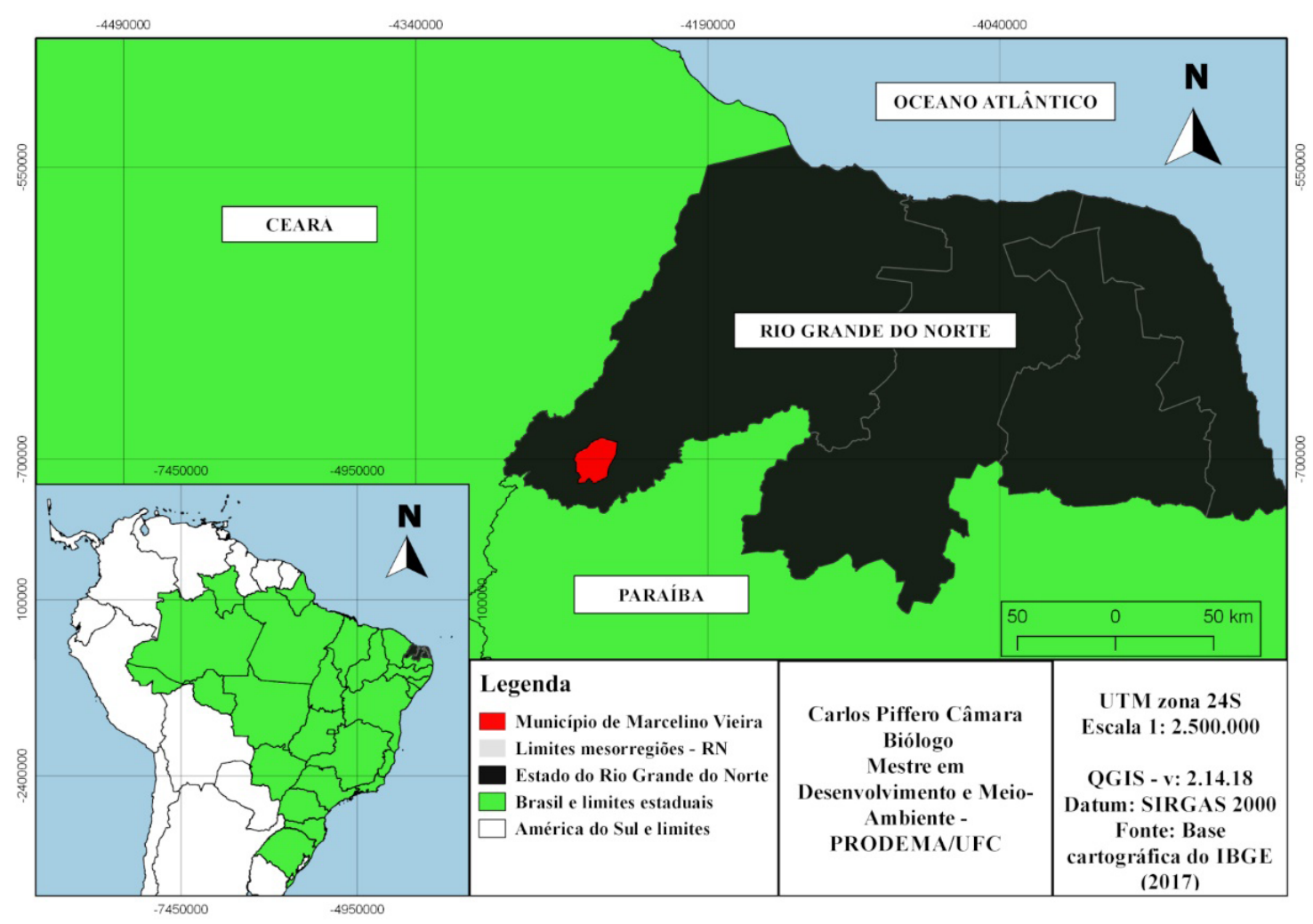

Fonte: Base Cartográfica IBGE (2017).

A pesquisa foi conduzida em quatro áreas diferentes (sítios 1-4) dentro do território de Marcelino Vieira - RN. As áreas selecionadas foram, respectivamente, Sítio 1 - Várzea do Canto

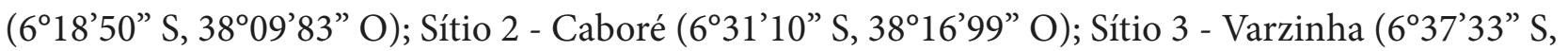

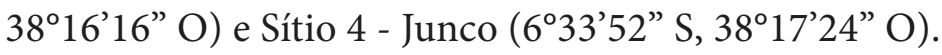


A região dos sítios é marcada por uma diversidade de formações da Caatinga e cultivos locais, por exemplo: no sítio 1 foram observadas áreas com Caatinga hiperxerófila (predomínio) e hipoxerófila, mata de galeria, áreas de plantio de culturas anuais como Zea mays L. (milho) e Sorghum bicolor (L.) Moench (sorgo); uma pequena área lacustre (açude), e quintais produtivos próximo as casas. Já no sítio 2, a vegetação é de Caatinga hiperxerófila, com plantio de culturas anuais, como o milho. No sítio 3, registraram-se áreas de Caatinga hipo (predomínio) e hiperxerófila, mata galeria, regiões com plantio de culturas anuais, como milho e abóbora, bem como quintais produtivos próximos as casas. Por fim, no sítio 4, verificou-se o predomínio de Caatinga hiperxerófila e uma grande área lacustre (açude Marcelino Vieira, principal reservatório da cidade).

\section{Métodos e técnicas}

Esta pesquisa foi realizada utilizando-se parâmetros quali-quantitativos. Inicialmente, o contato do pesquisador com os apicultores foi realizado por meio da técnica de "Rapport" (Bernard 2017), no intuito de criar uma ligação com os apicultores. Para a obtenção dos dados quantitativos realizou-se entrevistas estruturadas (Martin 1995), mediante aplicação de formulários, contendo questões abertas e fechadas que versam sobre o tema em pauta; diário de campo (Silva 2000), para registrar todos os acontecimentos ocorridos durante o dia de trabalho, bem como as percepções das pessoas com as quais foram mantidas contato e observação participante. Utilizou-se, ainda, a técnica turnê guiada (Spradley e Mccurdy 1972) para a validação dos nomes das espécies citadas nas entrevistas e de listas livres (Weller e Romney 1988) visando a obtenção de informações sobre as plantas usadas e as mudanças climáticas. A análise quantitativa dos dados foi realizada com a obtenção do Valor de Uso (VU) das espécies (Phillips e Gentry 1993), calculado por meio da razão entre o somatório das citações de uso para uma determinada espécie e o número total de informantes.

Como participantes, foram entrevistados 20 apicultores, todos integrantes da Associação Comunitária Jefferson Fernandes de Medeiros (ASCJFM), entidade que reúne os apicultores do local. Destaca-se que a amostra contemplou $83 \%$ dos atuais apicultores do município. Cada um dos entrevistados, individualmente, voluntariou-se a participar da pesquisa e assinou o Termo de Consentimento Livre e Esclarecido (TCLE), conforme Resolução CNS no 510/2016, após a aceitação e a compreensão dos objetivos da pesquisa, procedimentos e eventuais riscos (Brasil 2016). A pesquisa foi avaliada e aprovada pelo Comitê de Ética em Pesquisa da Universidade Federal do Ceará (UFC) sob parecer no 2.698.897 e cadastrada no Sistema Nacional de Gestão do Patrimônio Genético e do Conhecimento Tradicional Associado (SisGen) (número do cadastro A1BC7DE). Enquanto, as coletas de material botânico foram autorizadas pelo Sistema de Autorização e Informação em Biodiversidade (SISBIO) sob autorização de número 64026-1.

As coletas de dados socioeconômicos foram realizadas mediante formulário estruturado (Albuquerque et al. 2010) e durante a observação participante, com informações disponibilizadas pelos apicultores e pela ASCJFM. 


\section{Informações sobre o uso dos recursos florestais e as mudanças climáticas}

As informações sobre os recursos florestais foram obtidas através de formulários semiestruturados que resultaram nas listas livres 1 e 2. As listas foram elaboradas, respectivamente, a partir das perguntas: Quais plantas o senhor considera como medicinais? e Além das plantas que citou, faz uso de outras plantas para outros fins como: madeireiro, alimentício, artesanato, combustível, místico, uso doméstico, forragem, ou outro uso particular? (Roque e Loiola 2013). Com relação apenas as espécies vegetais consideradas medicinais, essas plantas foram categorizadas em diferentes tipos de doenças e problemas de saúde relacionados com os sistemas corporais reconhecidos pela Organização Mundial de Saúde (OMS 2017).

As amostras vegetais foram obtidas durante os meses de abril a junho de 2018, por meio da técnica turnê guiada (Albuquerque et al. 2010), que consistiu na indicação e coleta de amostras botânicas férteis, realizada na companhia de um ou mais entrevistados. O diário de campo (Minayo 2013) foi utilizado nessa ocasião para armazenar esses dados e informações sobre as plantas que foram indicadas durante a turnê guiada. As amostras vegetais foram herborizadas seguindo a metodologia do Manual Técnico da Vegetação Brasileira (IBGE 2012) e identificadas através de consultas a bibliografias especializadas e/ou por comparação com exemplares pertencentes ao acervo do Herbário Prisco Bezerra (EAC), da Universidade Federal do Ceará.

Também foram utilizadas as informações obtidas pelo Inventário Florístico Apícola Georreferenciado (IFAG 2017), cujas amostras estão depositadas no Herbário Prof. Francisco José de Abreu Matos - HUVA, da Universidade Estadual Vale do Acaraú, Sobral - CE, para complementar as listas livres 1 e 2 e a lista da turnê guiada. As espécies que não puderam ser encontradas "in situ", foram identificadas através da literatura e sites especializados. A grafia correta dos nomes dos táxons, a origem, endemismo e a forma de vida das espécies estão de acordo com o sítio do Projeto Flora do Brasil em Construção 2020 (2020).

As questões referentes a percepção dos apicultores sobre mudanças climáticas foram descritas no formulário semiestruturado. Quatros questões foram utilizadas para análise qualitativa e quantitativa sobre a percepção atual dos apicultores de Marcelino Vieira frente as mudanças climáticas em seu município.

\section{Análise de dados}

Os dados qualitativos e quantitativos, incluindo espécie, origem, hábito, categorias e formas de uso, bem como parte usada foram compilados por meio do programa Microsoft Office Excel. Além disso, o Valor de Uso (VU) das espécies citadas pelos apicultores foi calculado através da razão entre o somatório das citações de uso para uma determinada espécie e o número total de informantes, através da fórmula proposta por Lucena et al. (2012).

\section{Resultados e discussão}

\section{Espécies úteis de Marcelino Vieira - RN}

Os apicultores de Marcelino Vieira relataram 68 espécies úteis pertencentes a 38 famílias botânicas. As espécies são, em geral, nativas 43 (63\%) e apenas 25 (37\%) exóticas (Tabela 1). As 
famílias com maior número de citações foram Fabaceae (21\%), Lamiaceae (10\%) e Anacardiaceae (9\%). Merece destacar que Fabaceae compõe um importante grupo de plantas e representam a maior parte da diversidade florística da região Nordeste do Brasil e do Domínio fitogeográfico da Caatinga (BFG 2015; Amorim et al. 2016).

As plantas citadas corresponderam aos descritores alimentício, madeireiro, medicinal, combustível e forragem, não tendo registros para artesanato, místico e outro uso particular. Durante as entrevistas 16 (80\%) dos entrevistados citou mais de uma planta. Entre os descritores destacaramse o medicinal ( $62 \%$ das citações - Figura $2 \mathrm{~A}$ ), com maior número de citações, sendo indicadas 54 espécies, com potencial o tratamento de diversas doenças e/ou sintomas (Tabela 1).

Figura 2. Espécies vegetais registradas do município de Marcelino Vieira, RN. A. Percentual das espécies úteis identificadas pelos apicultores, conforme cinco descritores: alimentício, combustível, forragem, madeireiro e medicinal; B. Famílias botânicas mais representativas para uso medicinal na área de estudo.

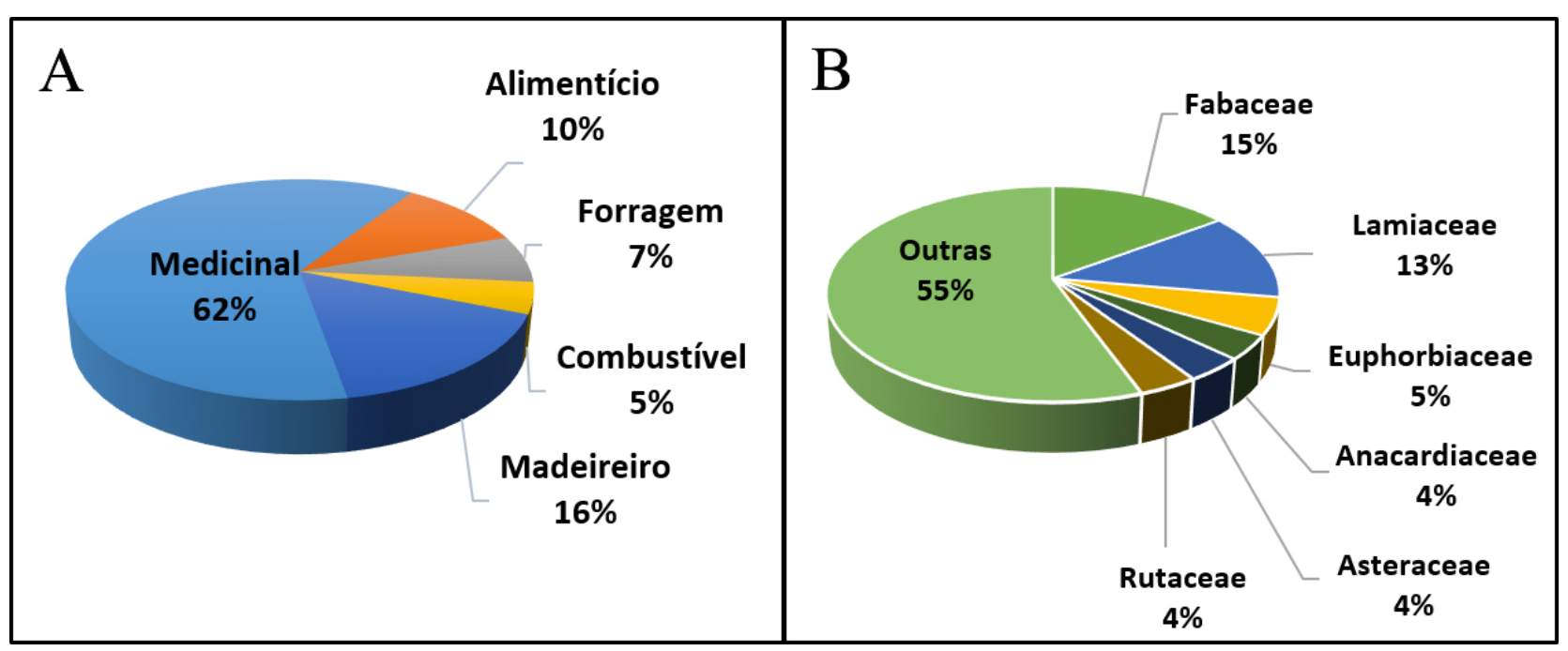

Fonte: elaborada pelos autores.

As espécies medicinais citadas quanto a forma de vida eram ervas (48\%), árvores (43\%), arbustos (7\%) e liana (apenas um representante). Um total de 36 famílias botânicas possui representantes identificados como medicinais, com destaque para Fabaceae (15\%), Lamiaceae (13\%), Euphorbiaceae (5\%), Anacardiaceae, Asteraceae e Rutaceae (4\% cada) (Figura 2B). Em outros levantamentos etnobotânicos realizados sobre espécies medicinas na Caatinga (Loiola et al. 2010; Roque et al. 2010; De Sá et al. 2015), Fabaceae também foi a família que apresentou o maior número de espécies citadas para esse descritor (Tabela 1).

Com relação ao valor de uso das espécies, Anacardium occidentale/ Cajueiro ( $\mathrm{VU}=0,45)$, Astronium urundeuval Aroeira ( $\mathrm{VU}=0,4)$ e Ximenia americanal Ameixa (VU $=0,35$ ) foram as que apresentaram os maiores valores de uso, e, por isso, consideradas as mais importantes quanto ao uso medicinal nessa pesquisa. Consultando a literatura científica verificou-se que no território potiguar apresenta similaridades e diferenças entre as espécies mais utilizadas em suas diferentes comunidades, por exemplo, em estudo realizado por Freitas et al. (2012), em São Miguel, $A$. occidentale também foi a espécie com maior número de citações de uso; enquanto na pesquisa desenvolvida por Roque et al. (2010), em Serra Negra do Norte foi A. urundeuva. 
Tabela 1. Espécies vegetais medicinais citadas pelos apicultores de Marcelino Vieira $-\mathrm{RN}$. OR= origem; $\mathrm{NA}=$ nativa; $\mathrm{EX}=$ exótica; $\mathrm{AV}=$ arbóreo; $\mathrm{AR}=$ arbustivo; $\mathrm{HE}=$ herbáceo; $\mathrm{SAR}=$ subarbustivo; $\mathrm{VU}=$ Valor de Uso. Categorias de Uso (OMS 2017): A - Lesões, envenenamento; B - Sintomas e sinais gerais; C - Doenças do aparelho respiratório; D - Doenças do aparelho digestivo; E - Doenças do aparelho circulatório; F - Doenças do aparelho geniturinário; G - Doenças da pele e tecido subcutâneo; H Doenças do sangue e dos órgãos hematopoiéticos e de alguns transtornos imunitários; I - Neoplasias. Formas de Uso: I - Chá; II - Garrafada; III- Inalação; IV - In natura; V - Lambedor; VI - Óleo; VII Pílula; VIII - Pó; IX - Sabonete; X - Xarope. NR = Número de Registro no Herbário Prisco Bezerra (EAC) e Prof. Francisco José de Abreu Matos (HUVA); il: identificação local; ilt: identificação literatura.

\begin{tabular}{|c|c|c|c|c|c|c|c|c|}
\hline Família & $\begin{array}{l}\text { Nome Científico/ } \\
\text { Popular }\end{array}$ & OR & Hábito & VU & $\begin{array}{l}\text { Categorias } \\
\text { de uso } \\
\text { (OMS) } \\
\end{array}$ & $\begin{array}{l}\text { Formas } \\
\text { de Uso }\end{array}$ & $\begin{array}{l}\text { Parte } \\
\text { Usada }\end{array}$ & NR \\
\hline Amarantaceae & $\begin{array}{l}\text { Gomphrena demissa } \\
\text { Mart. / Orós ou Oró }\end{array}$ & NA & $\mathrm{HE}$ & 0,15 & $\mathrm{C}$ & V & Raiz & $\begin{array}{l}\text { EAC } \\
62127\end{array}$ \\
\hline \multirow[t]{2}{*}{ Anacardiaceae } & $\begin{array}{l}\text { Anacardium } \\
\text { occidentale L. / } \\
\text { Cajueiro }\end{array}$ & NA & AV & 0,45 & $\mathrm{~A} ; \mathrm{B} ; \mathrm{D} ; \mathrm{F}$ & I; II & Casca & $\begin{array}{l}\text { HUVA } \\
21412\end{array}$ \\
\hline & $\begin{array}{l}\text { Astronium } \\
\text { urundeuva } \\
\text { (M.Allemão) Engl. }\end{array}$ & NA & AV & 0,4 & $\mathrm{~B} ; \mathrm{C} ; \mathrm{H}$ & $\begin{array}{l}\text { I, II; IX; } \\
\quad \mathrm{X}\end{array}$ & Casca & $\begin{array}{l}\text { HUVA } \\
21425\end{array}$ \\
\hline Annonaceae & $\begin{array}{l}\text { Annona muricata L. } \\
\text { / Graviola }\end{array}$ & EX & AV & 0,15 & B; D; E; I & I & Folha & ilt. \\
\hline \multirow[t]{2}{*}{ Apiaceae } & $\begin{array}{l}\text { Anethum graveolens } \\
\text { L. / Endro }\end{array}$ & EX & $\mathrm{HE}$ & 0,05 & B; E & I & Semente & ilt. \\
\hline & $\begin{array}{l}\text { Pimpinella anisum } \\
\text { L. / Erva-doce }\end{array}$ & EX & $\mathrm{HE}$ & 0,05 & $\mathrm{E}$ & I & Semente & ilt. \\
\hline \multirow[t]{2}{*}{ Asteraceae } & $\begin{array}{l}\text { Achyrocline } \\
\text { satureioides (Lam.) } \\
\text { DC. / Macela }\end{array}$ & EX & $\mathrm{HE}$ & 0,1 & B; D & I & $\begin{array}{l}\text { Fruto e } \\
\text { Caroço; } \\
\text { Flor }\end{array}$ & ilt. \\
\hline & $\begin{array}{l}\text { Helianthus annuus } \\
\text { L. / Girassol }\end{array}$ & EX & $\mathrm{HE}$ & 0,05 & B & I & Semente & ilt. \\
\hline Asphodelaceae & $\begin{array}{l}\text { Aloe vera (L.) Burm. } \\
\text { / Babosa }\end{array}$ & EX & $\mathrm{HE}$ & 0,15 & B & II; VII & Folha & ilt. \\
\hline Brassicaceae & $\begin{array}{l}\text { Nasturtium } \\
\text { officinale Robert } \\
\text { Brown. / Agrião }\end{array}$ & EX & $\mathrm{HE}$ & 0,1 & $\mathrm{C}$ & I; V & Folha & ilt. \\
\hline Burseraceae & $\begin{array}{l}\text { Commiphora } \\
\text { leptophloeos (Mart.) } \\
\text { J. B. Gillett. / } \\
\text { Imburana }\end{array}$ & NA & AV & 0,05 & $\mathrm{C}$ & $\mathrm{X}$ & Fruto & ilt. \\
\hline Cactaceae & $\begin{array}{l}\text { Cereus jamacaru. } \\
\text { DC. / Mandacaru }\end{array}$ & NA & AV & 0,05 & $\mathrm{~F}$ & I & Raiz & il. \\
\hline Chenopodiaceae & $\begin{array}{l}\text { Chenopodium } \\
\text { ambrosioides L./ } \\
\text { Mastruz }\end{array}$ & EX & SAR & 0,1 & B & I; IV & Folha & ilt. \\
\hline Cleomaceae & $\begin{array}{l}\text { Tarenaya longicarpa } \\
\text { Soares Neto } \\
\text { \& Roalson. / } \\
\text { Mussambé }\end{array}$ & NA & SAR & 0,2 & $\mathrm{~B} ; \mathrm{C}$ & $\mathrm{I} ; \mathrm{V}$ & $\begin{array}{l}\text { Casca; } \\
\text { Flor; } \\
\text { Raiz }\end{array}$ & $\begin{array}{l}\text { HUVA } \\
20605\end{array}$ \\
\hline
\end{tabular}




\begin{tabular}{|c|c|c|c|c|c|c|c|c|}
\hline Família & $\begin{array}{l}\text { Nome Científico/ } \\
\text { Popular }\end{array}$ & OR & Hábito & VU & $\begin{array}{l}\text { Categorias } \\
\text { de uso } \\
\text { (OMS) }\end{array}$ & $\begin{array}{l}\text { Formas } \\
\text { de Uso }\end{array}$ & $\begin{array}{l}\text { Parte } \\
\text { Usada }\end{array}$ & NR \\
\hline Combretaceae & $\begin{array}{l}\text { Combretum } \\
\text { leprosum Mart. / } \\
\text { Mofumbo }\end{array}$ & NA & $\mathrm{AR}$ & 0,2 & $\mathrm{C}$ & II; V & Casca & $\begin{array}{l}\text { HUVA } \\
20538\end{array}$ \\
\hline Crassulaceae & $\begin{array}{l}\text { Kalanchoe } \\
\text { brasiliensis Camb. / } \\
\text { Corama }\end{array}$ & EX & $\mathrm{HE}$ & 0,05 & $\mathrm{C}$ & V & Folha & ilt. \\
\hline \multirow[t]{3}{*}{ Euphorbiaceae } & $\begin{array}{l}\text { Croton } \\
\text { blanchetianus Bail. / } \\
\text { Marmeleiro }\end{array}$ & NA & $\mathrm{AR}$ & 0,2 & $\mathrm{~B} ; \mathrm{D}$ & I; IV; V & Casca & il. \\
\hline & $\begin{array}{l}\text { Croton } \\
\text { heliotropiifolius } \\
\text { Kunth. / Velame }\end{array}$ & NA & $\mathrm{AR}$ & 0,05 & B & I & Folha & $\begin{array}{l}\text { HUVA } \\
20571\end{array}$ \\
\hline & $\begin{array}{l}\text { Jatropha mollisima } \\
\text { L. / Pião }\end{array}$ & NA & $\mathrm{HE}$ & 0,05 & B & - & $\begin{array}{l}\text { Flor; } \\
\text { Casca }\end{array}$ & $\begin{array}{l}\text { HUVA } \\
20563\end{array}$ \\
\hline \multirow[t]{9}{*}{ Fabaceae } & $\begin{array}{l}\text { Amburana cearensis } \\
\text { (Allem.) A. C. } \\
\text { Smith. / Cumaru }\end{array}$ & NA & AV & 0,2 & $\mathrm{C}$ & I; III; V & Casca & ilt. \\
\hline & $\begin{array}{l}\text { Anadenanthera } \\
\text { colubrina (Vell.) } \\
\text { Brenan / Angico }\end{array}$ & NA & AV & 0,15 & $\mathrm{~B} ; \mathrm{C}$ & I; V & Casca & $\begin{array}{l}\text { HUVA } \\
21484\end{array}$ \\
\hline & $\begin{array}{l}\text { Arachis hypogaea L. } \\
\text { / Amendoim }\end{array}$ & $\mathrm{EX}$ & $\mathrm{HE}$ & 0,05 & B & VI & Semente & ilt. \\
\hline & $\begin{array}{l}\text { Bauhinia sp. / } \\
\text { Mororó }\end{array}$ & NA & AV & 0,1 & B & I & Casca & il. \\
\hline & $\begin{array}{l}\text { Hymenaea courbaril } \\
\text { L./Jatobá }\end{array}$ & NA & AV & 0,05 & B & IV & Casca & ilt. \\
\hline & $\begin{array}{l}\text { Libidibia ferrea } \\
\text { (Mart. ex Tul.) L.P. } \\
\text { Queiroz/ Jucá }\end{array}$ & NA & AV & 0,05 & B & IV & Fruto & il. \\
\hline & $\begin{array}{l}\text { Luetzelburgia } \\
\text { auriculata } \\
\text { (Allemão) Ducke / } \\
\text { Pau-mocó }\end{array}$ & NA & AV & 0,05 & B & IV & Raiz & $\begin{array}{l}\text { EAC } \\
62132\end{array}$ \\
\hline & $\begin{array}{l}\text { Mimosa tenuiflora } \\
\text { (Willd.) Poir. / } \\
\text { Jurema-preta }\end{array}$ & NA & AV & 0,2 & B & I; V & Casca & $\begin{array}{l}\text { HUVA } \\
21424\end{array}$ \\
\hline & $\begin{array}{l}\text { Poincianella } \\
\text { pyramidalis (Tul.) } \\
\text { L.P. Queiroz / } \\
\text { Catingueira }\end{array}$ & NA & AV & 0,05 & $\mathrm{C}$ & I & $\begin{array}{l}\text { Casca; } \\
\text { Flor }\end{array}$ & $\begin{array}{l}\text { HUVA } \\
20553\end{array}$ \\
\hline \multirow[t]{2}{*}{ Lamiaceae } & $\begin{array}{l}\text { Lavandula } \\
\text { officinalis L./ } \\
\text { Alfazema }\end{array}$ & EX & $\mathrm{HE}$ & 0,05 & $\mathrm{D}$ & I & $\begin{array}{l}\text { Casca; } \\
\text { Flor; } \\
\text { Folha }\end{array}$ & ilt. \\
\hline & $\begin{array}{l}\text { Marsypianthes } \\
\text { chamaedrys (Vahl) } \\
\text { Kuntze / Bamburral }\end{array}$ & NA & $\mathrm{HE}$ & 0,05 & C; D & I & $\begin{array}{l}\text { Caule; } \\
\text { Semente }\end{array}$ & $\begin{array}{l}\text { HUVA } \\
20570\end{array}$ \\
\hline
\end{tabular}




\begin{tabular}{|c|c|c|c|c|c|c|c|c|}
\hline Família & $\begin{array}{l}\text { Nome Científico/ } \\
\text { Popular }\end{array}$ & OR & Hábito & VU & $\begin{array}{l}\text { Categorias } \\
\text { de uso } \\
\text { (OMS) }\end{array}$ & $\begin{array}{c}\text { Formas } \\
\text { de Uso }\end{array}$ & $\begin{array}{l}\text { Parte } \\
\text { Usada }\end{array}$ & NR \\
\hline & $\begin{array}{l}\text { Mesosphaerum } \\
\text { suaveolens }(\mathrm{L} .) \\
\text { Kuntze / Bamburral }\end{array}$ & NA & $\mathrm{HE}$ & 0,05 & $C ; D$ & I & $\begin{array}{l}\text { Caule; } \\
\text { Semente }\end{array}$ & $\begin{array}{l}\text { HUVA } \\
20566\end{array}$ \\
\hline & $\begin{array}{l}\text { Mentha piperita L. / } \\
\text { Hortelã }\end{array}$ & $\mathrm{EX}$ & $\mathrm{HE}$ & 0,15 & $\mathrm{~B} ; \mathrm{C}$ & I; V & Folha & ilt. \\
\hline & $\begin{array}{l}\text { Vitex gardneriana } \\
\text { Schauer. / } \\
\text { Jaramataia }\end{array}$ & NA & AV & 0,1 & $\mathrm{~F}$ & I & Folha & il. \\
\hline & $\begin{array}{l}\text { Melochia } \\
\text { pyramidata L. / } \\
\text { Malva }\end{array}$ & & $\mathrm{HE}$ & 0,1 & $\mathrm{C}$ & I; V & Folha & $\begin{array}{l}\text { HUVA } \\
20588\end{array}$ \\
\hline & $\begin{array}{l}\text { Mesosphaerum } \\
\text { pectinatum (L.) } \\
\text { Kuntze/ Samba- } \\
\text { coité ou Alfazema- } \\
\text { brava }\end{array}$ & NA & $\mathrm{HE}$ & 0,15 & B; C; D & I & $\begin{array}{l}\text { Caule; } \\
\text { Folha; } \\
\text { Semente }\end{array}$ & $\begin{array}{l}\text { HUVA } \\
20591\end{array}$ \\
\hline Lauraceae & $\begin{array}{l}\text { Persea americana } \\
\text { Mill. / Abacate }\end{array}$ & EX & AV & 0,05 & $\mathrm{E}$ & I & Folha & ilt. \\
\hline Loranthaceae & $\begin{array}{l}\text { Struthanthus } \\
\text { polyrhysus Mart. / } \\
\text { Esterco-passarinho } \\
\text { ou Erva-Passarinho }\end{array}$ & EX & $\mathrm{HE}$ & 0,05 & $\mathrm{C}$ & $\mathrm{V} ; \mathrm{X}$ & Fruto & il. \\
\hline Lythraceae & $\begin{array}{l}\text { Punica granatum L. } \\
\text { / Romã }\end{array}$ & EX & $\mathrm{AR}$ & 0,05 & $\mathrm{C}$ & IV & Fruto & il. \\
\hline Malpighiaceae & $\begin{array}{l}\text { Malpighia glabra L./ } \\
\text { Acerola }\end{array}$ & EX & $\mathrm{AR}$ & 0,2 & $\mathrm{~B} ; \mathrm{C}$ & IV; V & Fruto & il. \\
\hline Musaceae & $\begin{array}{l}\text { Musa sp. / } \\
\text { Bananeira }\end{array}$ & EX & $\mathrm{HE}$ & 0,05 & $\mathrm{C}$ & V & Flor & ilt. \\
\hline Myrtaceae & $\begin{array}{l}\text { Psidium guajava L. / } \\
\text { Goiaba }\end{array}$ & NA & AV & 0,05 & $\mathrm{D}$ & I & $\begin{array}{l}\text { Folha } \\
\text { jovem }\end{array}$ & il. \\
\hline Olacaceae & $\begin{array}{l}\text { Ximenia americana } \\
\text { L. / Ameixa }\end{array}$ & NA & AV & 0,35 & B; D & $\begin{array}{l}\text { I; II; } \\
\text { VIII }\end{array}$ & Casca & $\begin{array}{l}\text { EAC } \\
\mathrm{s} / \mathrm{n}\end{array}$ \\
\hline Passifloraceae & $\begin{array}{l}\text { Passiflora edulis } \\
\text { Sims / Maracujá }\end{array}$ & EX & Liana & 0,05 & B & IV & Fruto & ilt. \\
\hline Pedaliaceae & $\begin{array}{l}\text { Sesamum indicum } \\
\text { L. / Gergelim }\end{array}$ & EX & $\mathrm{HE}$ & 0,05 & B & VI & Semente & ilt. \\
\hline Phyllanthaceae & $\begin{array}{l}\text { Phyllanthus amarus } \\
\text { Schum et Thorn. / } \\
\text { Quebra-pedra }\end{array}$ & NA & $\mathrm{HE}$ & 0,05 & $\mathrm{~F}$ & I & $\begin{array}{l}\text { Raiz; } \\
\text { Ramo }\end{array}$ & ilt. \\
\hline Poaceae & $\begin{array}{l}\text { Cymbopogon } \\
\text { citratus (DC.) Stapf. } \\
\text { / Capim-santo }\end{array}$ & NA & $\mathrm{HE}$ & 0,05 & B & I & Folha & ilt. \\
\hline Rhamaceae & $\begin{array}{l}\text { Sarcomphalus } \\
\text { joazeiro (Mart.) } \\
\text { Hauenshild / } \\
\text { Joazeiro }\end{array}$ & NA & AV & 0,15 & $B ; D ; G$ & I; IV; V & $\begin{array}{l}\text { Casca; } \\
\text { Casca }\end{array}$ & $\begin{array}{l}\text { HUVA } \\
21481\end{array}$ \\
\hline
\end{tabular}




\begin{tabular}{|c|c|c|c|c|c|c|c|c|}
\hline Família & $\begin{array}{l}\text { Nome Científico/ } \\
\text { Popular }\end{array}$ & OR & Hábito & VU & $\begin{array}{l}\text { Categorias } \\
\text { de uso } \\
\text { (OMS) }\end{array}$ & $\begin{array}{l}\text { Formas } \\
\text { de Uso }\end{array}$ & $\begin{array}{l}\text { Parte } \\
\text { Usada }\end{array}$ & NR \\
\hline Rubiaceae & $\begin{array}{l}\text { Coutarea hexandra } \\
\text { (Jacq.) K. Selwen H. } \\
\text { S. Irwin e Barnaby / } \\
\text { Quina-quina }\end{array}$ & NA & AV & 0,05 & B & I & Casca & $\begin{array}{l}\text { EAC } \\
62137\end{array}$ \\
\hline \multirow[t]{2}{*}{ Rutaceae } & $\begin{array}{l}\text { Citrus sinensis L. / } \\
\text { Laranja }\end{array}$ & EX & AV & 0,05 & $\mathrm{~B} ; \mathrm{C}$ & IV & - & ilt. \\
\hline & $\begin{array}{l}\text { Citrus aurantifolia } \\
\text { Swing var. taiti / } \\
\text { Limão }\end{array}$ & EX & AV & 0,1 & B; D & I; IV & $\begin{array}{l}\text { Casca; } \\
\text { Fruto; }\end{array}$ & il. \\
\hline Sapotaceae & $\begin{array}{l}\text { Sideroxylon } \\
\text { obtusifolium } \\
\text { (Roem. \& Schult.) } \\
\text { T.D.Penn./ Quixaba }\end{array}$ & NA & AV & 0,05 & B & I & Casca & ilt. \\
\hline Solanaceae & $\begin{array}{l}\text { Solanum sp. / } \\
\text { Melancia-da-praia }\end{array}$ & NA & $\mathrm{HE}$ & 0,05 & $\mathrm{~F}$ & I & Raiz & ilt. \\
\hline Turneraceae & $\begin{array}{l}\text { Turnera subulata } \\
\text { Sm. / Chanana }\end{array}$ & NA & SAR & 0,05 & B & I & Raiz & $\begin{array}{l}\text { HUVA } \\
20576\end{array}$ \\
\hline Verbenaceae & $\begin{array}{l}\text { Lippia alba (Mill.) } \\
\text { N.E.Br. ex P. Wilson } \\
\text { / Cidreira. }\end{array}$ & EX & $\mathrm{HE}$ & 0,25 & B & I & $\begin{array}{l}\text { Folha; } \\
\text { Caule }\end{array}$ & ilt. \\
\hline
\end{tabular}

Fonte: elaborada pelos autores.

Com relação ao valor de uso das espécies, Anacardium occidentale/ Cajueiro (VU = 0,45), Astronium urundeuval Aroeira (VU $=0,4)$ e Ximenia americanal Ameixa (VU =0,35) foram as que apresentaram os maiores valores de uso, e, por isso, consideradas as mais importantes quanto ao uso medicinal nessa pesquisa. Consultando a literatura científica verificou-se que no território potiguar apresenta similaridades e diferenças entre as espécies mais utilizadas em suas diferentes comunidades, por exemplo, em estudo realizado por Freitas et al. (2012), em São Miguel, A. occidentale também foi a espécie com maior número de citações de uso; enquanto, na pesquisa desenvolvida por Roque et al. (2010), em Serra Negra do Norte foi A. urundeuva.

Roque et al. (2010) verificaram que as comunidades rurais estão, de modo geral, intimamente ligadas aos usos de plantas medicinais. O uso dessas plantas sempre esteve presente ao longo da história da humanidade e permanece até os dias atuais, fazendo parte da cultura de diferentes comunidades, em especial, em áreas rurais (Marodin e Baptista 2002; Cabral e Maciel 2011). Esse uso tem importante impacto econômico para as comunidades, de forma que a utilização dessas espécies, muitas vezes nativas da região ou cultivadas em seu quintal, pode reduzir os gastos com medicamentos sintéticos. Algumas famílias brasileiras, principalmente de baixo poder aquisitivo, geralmente têm em casa crianças e idosos, e a aquisição de medicamentos sintéticos pode representar um custo considerável dentro do limitado orçamento doméstico (Cabral e Maciel 2011).

Em uma perspectiva comparativa, as dez principais espécies medicinais registradas no município de Marcelino Vieira também foram citadas em diversos outros estudos realizados no Nordeste brasileiro. A similaridade dessas espécies com outros estudos etnobotânicos para a 
Caatinga, considerando também o número de espécies citadas em cada localidade (município) é apresentada na Tabela 2.

Entre os estudos elencados acima realizados no âmbito da Caatinga sobre plantas medicinais e considerando as espécies com o VU $\geq 0.2$ (Tabela 2) foi encontrada uma similaridade considerável com os resultados obtidos por Silva e Freire (2010) em Serra Negra - RN e Ribeiro et al. (2014) em Assaré - CE com $80 \%$ e 70\%, respectivamente. Ressalta-se que entre as espécies com VU $\geq 0.2$, apenas Lippia alba (cidreira) consta na lista da ANVISA (2017) como planta medicinal. As mesmas indicações de uso dos apicultores de Marcelino Vieira para as plantas listadas na Tabela 2, também foram relatadas no estudo desenvolvido por Baracuhy et al. (2016) na região Nordeste do Brasil.

Tabela 2. Similaridade das principais espécies medicinais citadas pelos apicultores para o município Marcelino Vieira - RN (VU $\geq 0.2)$ com outros estudos realizados na Caatinga nordestina. Legenda: A - Anacardium occidentale L.; B-Astronium urundeuva (M.Allemão); C - Tarenaya spinosa (Jacq.) Raf.; D - Combretum leprosum Mart.; F - Amburana cearensis (Allemão) A.C.Sm.; G - Mimosa tenuiflora (Willd.) Poir.; H - Malpighia glabra L.; I - Ximenia americana L.; J - Lippia alba (Mill.) N.E.Br. ex Britton \& P.Wilson.

\begin{tabular}{llclc}
\hline $\begin{array}{l}\text { Referência } \\
\text { Bibliográfica }\end{array}$ & Localidade & $\begin{array}{c}\text { Número de espécies } \\
\text { citadas em estudos } \\
\text { etnobotânicos na } \\
\text { Caatinga }\end{array}$ & $\begin{array}{l}\text { Espécies em } \\
\text { comum }\end{array}$ & \% similaridade \\
\hline Mosca e Loiola (2009) & Natal - RN & 57 & A; J & 20 \\
Roque et al. (2010) & Caicó - RN & 62 & B; D; F; I & 40 \\
Silva e Freire (2010) & Serra Negra - RN & 45 & A; B; D; E; F; H; I; J & 80 \\
Almeida (2011) & Jeremoabo - BA & 86 & A; E; G; I; J & 50 \\
Freitas et al. (2012) & São Miguel - RN & 60 & A; B; F; H; J & 50 \\
Lucena et al. (2012) & Soledade - PB & 101 & B; F; G & 30 \\
Roque e Loiola (2013) & Caicó - RN & 69 & B; C; D; F; G; I & 60 \\
Ribeiro et al. (2014) & Assaré - CE & 116 & A; B; C; F; G; I; J & 70 \\
Silva et al. (2015) & Milagres - CE & 62 & A; B; F; G; I & 50 \\
\hline
\end{tabular}

Fonte: elaborada pelo autores.

As espécies medicinais foram, ainda, enquadradas em nove categorias de classificação segundo a Organização Mundial da Saúde (OMS 2017). As categorias que apresentaram maior importância comparativamente, conforme o número de citações foram: B - Sintomas e sinais gerais (42\%); C Doenças do aparelho respiratório (26\%); D - Doenças do aparelho digestivo (16\%). Entre doenças e sintomas as que tiveram maior citação foram gripe (20\%), inflamação (12\%) e cicatrização (10\%), respectivamente.

Um total de 10 formas de preparo das plantas foram mencionadas pelos apicultores de Marcelino Vieira, sendo o chá $(54,4 \%)$ o método de preparo mais citado para curar as enfermidades, seguido de lambedor (22,05\%) e in natura (16,17\%). Padrão semelhante foi reportado por Silva et al. (2015) em um estudo desenvolvido no município de Milagres - CE. Com relação as partes das plantas mais utilizadas para o uso medicinal, destacaram-se a casca (41\%), folha (22\%), raiz (10\%) e frutos (9\%). 
Essa informação indica que as plantas medicinais disponíveis no local fornecem estruturas perenes (cascas, entrecascas e raízes) para o uso medicinal, de forma que 90\% relatou que não armazenam as partes das plantas para usos futuro e, quando necessitam, retiram diretamente da mata.

Outro importante recurso medicinal utilizado pelos apicultores é o uso da picada de Apis mellifera Linnaeus, 1758 para a redução de dor na coluna e artrite, sendo indicado por 5 (25\%) dos entrevistados. Sabe-se que a apitoxina, o "veneno" provindo do ferrão dessa espécie de abelha, tem propriedades comprovadas para melhoria desses sintomas (Schirmer 1985; Moreira 2012; Dantas et al. 2013). A eficácia da Apiterapia no tratamento artrítico é basicamente para aliviar as dores, estimulando os pontos musculares dolorosos (Moreira 2012). Outras funcionalidades ainda vêm sendo descritas como tratamento de doenças autoimunes, contra o câncer, doenças de pele e infecções (Dantas et al. 2013).

As plantas úteis para outros fins corresponde à lista livre 2 (Tabela 3) e está representada por 30 espécies vegetais, sendo os representantes das famílias Fabaceae (34\%) e Anacardiaceae (20\%) os mais citados. O segundo descritor com maior número de citações foi o madeireiro (43\%), seguido de alimentício (27\%), forragem (18\%) e combustível (12\%). Para o grupo das plantas úteis para outros fins, as espécies com maior valor de uso (VU) foram Croton blanchetianus/ Marmeleiro $(0,65)$, Anacardium occidentale/ Cajueiro (0,5), Anadenanthera colubrina/ Angico (0.4), Amburana cearensis/ Cumaru $(0,4)$ e Astronium urundeuva/ Aroeira (0,35). Destaca-se, no entanto, que devido suas potencialidades, essas plantas podem estar sofrendo elevada pressão de uso e provavelmente, necessitam de estratégias para sua conservação no ambiente, conforme já enfatizado por Lucena et al. (2012).

Especificamente quanto ao uso madeireiro, que correspondeu a 16\% das indicações, as plantas mais citadas foram Croton blanchetianus, Anadenanthera colubrina e Amburana cearensis (Tabela 3). O uso alimentício correspondeu a $10 \%$ das citações e entre as nove espécie citadas para esse descritor destacaram-se Anacardium occidentale/ Cajueiro, Psidium guajava/ Goiaba e Malpighia glabral Acerola.

Tabela 3. Indicação das plantas úteis para outros fins. Legenda: MA (Madeireiro); AL (Alimentício); FO (Forragem); CO (Combustível). OR (Origem); NA (Nativa); EX (Exótica); AR (Arbustivo); AV (Arbóreo); HE (Herbáceo); SAR (Subarbustivo). VU (Valor de Uso).

\begin{tabular}{lllcccc}
\hline Família & Nome Cientifico & Nome popular & Usos & OR & Hábito & VU \\
\hline Anacardiaceae & Anacardium occidentale L. & Cajueiro & AL & NA & AV & 0,5 \\
& $\begin{array}{l}\text { Astronium urundeuva (M.Allemão) } \\
\text { Engl. }\end{array}$ & Aroeira & MA & NA & AV & 0,35 \\
& Spondias macrocarpa Engl. & Cajarana & AL & NA & AV & 0,3 \\
& Spondias mombin L. & Cajazeira & AL & NA & AV & 0,05 \\
& Spondias purpurea L. & Seriguela & AL & NA & AV & 0,1 \\
& Spondias tuberosa Arruda. & Imbuzeiro & AL & NA & AV & 0,05 \\
Annonaceae & Annona muricata L. & Graviola & AL & EX & AV & 0,05 \\
Apocynaceae & Aspidosperma pyrifolium Mart. & Pereiro & MA; & NA & AV & 0,2 \\
& Handroanthus heptaphyllus (Vell.) & Pau-arco & MA & NA & AV & 0,05
\end{tabular}




\begin{tabular}{|c|c|c|c|c|c|c|}
\hline Família & Nome Cientifico & Nome popular & Usos & OR & Hábito & VU \\
\hline Burseraceae & $\begin{array}{l}\text { Commiphora leptophloeos (Mart.) J.B. } \\
\text { Gillett. }\end{array}$ & Imburana & $\begin{array}{l}\text { MA; } \\
\text { ME }\end{array}$ & NA & AV & 0,05 \\
\hline Cleomaceae & Tarenaya spinosa (Jacq.) Raf. & Mussambé & $\mathrm{CO}$ & NA & SAR & 0,05 \\
\hline Combretaceae & Combretum leprosum Mart. & Mofumbo & MA & NA & $\mathrm{AR}$ & 0,15 \\
\hline Euphorbiaceae & Croton blanchetianus Baill. & Marmeleiro & $\begin{array}{l}\text { MA; } \\
\text { CO }\end{array}$ & NA & $\mathrm{AR}$ & 0,65 \\
\hline \multirow[t]{11}{*}{ Fabaceae } & $\begin{array}{l}\text { Amburana cearensis (Allem.) A. C. } \\
\text { Smith }\end{array}$ & Cumaru & MA & NA & ÁV & 0,4 \\
\hline & $\begin{array}{l}\text { Anadenanthera colubrina (Vell.) } \\
\text { Branan. }\end{array}$ & Angico & MA & NA & AV & 0,4 \\
\hline & Bauhinia sp. & Mororó & MA & NA & AV & 0,2 \\
\hline & $\begin{array}{l}\text { Enterolobium contortisiliquum (Vell.) } \\
\text { Morong. }\end{array}$ & Timbauba & MA; & NA & AV & 0,2 \\
\hline & Mimosa caesalpiniifolia Benth. & Sabiá & MA & NA & AV & 0,05 \\
\hline & Mimosa tenuiflora (Willd.) Poir. & Jurema-preta & MA & NA & AV & 0,05 \\
\hline & Piptadenia stipulacea (Kunth.) Benth & Jurema & MA & NA & AV & 0,15 \\
\hline & $\begin{array}{l}\text { Poincianella pyramidalis (Tul.) L.P. } \\
\text { Queiroz }\end{array}$ & Catingueira & $\begin{array}{l}\mathrm{FO} \\
\mathrm{CO}\end{array}$ & NA & AV & 0,15 \\
\hline & Prosopis juliflora (Sw.) DC. & Algaroba & $\begin{array}{l}\mathrm{MA} \\
\mathrm{CO}\end{array}$ & $\mathrm{EX}$ & AV & 0,15 \\
\hline & $\begin{array}{l}\text { Senna uniflora (Mill.) H.S.Irwin \& } \\
\text { Barneby }\end{array}$ & Mata-pasto & $\mathrm{FO}$ & NA & $\mathrm{HE}$ & 0,1 \\
\hline & $\begin{array}{l}\text { Senna spectabilis (DC.) H.S.Irwin \& } \\
\text { Barneby var. excelsa (Schrad.) H.S. } \\
\text { Irwin \& Barneby }\end{array}$ & Canafístula & $\begin{array}{l}\text { MA; } \\
\text { FO }\end{array}$ & NA & $\mathrm{AR}$ & 0,1 \\
\hline Malpighiaceae & Malpighia glabra L. & Acerola & $\mathrm{AL}$ & $\mathrm{EX}$ & AV & 0,2 \\
\hline Musaceae & Musa sp. & Banana & $\mathrm{AL}$ & $\mathrm{EX}$ & $\mathrm{HE}$ & 0,05 \\
\hline Myrtaceae & Psidium guajava L. & Goiaba & $\mathrm{AL}$ & NA & AV & 0,25 \\
\hline \multirow[t]{2}{*}{ Poaceae } & Sorghum bicolor (L.) Moench & Sorgo & $\mathrm{FO}$ & $\mathrm{EX}$ & $\mathrm{HE}$ & 0,1 \\
\hline & Zea mays $\mathrm{L}$. & Milho & $\mathrm{FO}$ & EX & $\mathrm{HE}$ & 0,1 \\
\hline Rhamnaceae & $\begin{array}{l}\text { Sarcomphalus joazeiro (Mart.) } \\
\text { Hauenshild }\end{array}$ & Joazeiro & $\mathrm{FO}$ & NA & AV & 0,1 \\
\hline
\end{tabular}

Fonte: elaborada pelos autores.

Três espécies nativas de Fabaceae foram citadas como importantes forrageiras para bovinos e caprinos: Poincianella pyramidalis/ Catingueira, Senna uniflora/ Mata pasto e Senna spectabilis/ Canafístula (Tabela 3). Seis espécies foram identificadas para forragem, das quais quatro são nativas e duas exóticas (Zea mays L. / Milho e Sorghum bicolor (L.) Moench / Sorgo). Com relação ao descritor combustível (lenha), Croton blanchetianus se destacou com o maior número de citações. 
Considerando os descritores levantados em Marcelino Vieira, as espécies mais versáteis foram Croton sonderianus/ Marmeleiro (madeireiro, combustível e medicina) e Poincianella pyramidalis/ Catingueira (forragem, combustível e medicinal).

\section{Mudanças climáticas na visão de apicultores do semiárido potiguar}

De acordo com a percepção dos apicultores sobre as florestas e seus recursos, 19 (95\%) acreditam que estas abrigam plantas que poderão ajudar na cura de doenças no futuro. Além disso, 12 (60\%) afirmaram que as florestas estão diminuindo no município de Marcelino Vieira - RN. É importante destacar, que embora as queimadas não tenham sido citadas como uma prática local, foram encontrados indícios de fogo na vegetação em duas áreas visitadas, além de registro de um forno para produção de carvão. Ademais, dados recentes do Serviço Florestal Brasileiro (SFB 2018) indicam que o município possui apenas $15,85 \%$ de florestas naturais. Essa redução das florestas pode ter sua influência do desmatamento de áreas preservadas, para uso madeireiro (estacas, mourões) ou para utilização como combustível em fogões a lenha ou a carvão vegetal.

Nesse contexto, 14 (70\%) dos entrevistados afirmaram que as mudanças climáticas têm afetado sua vida. Os apicultores $(17,85 \%)$ destacam, ainda, que o clima está mudando, como observam nas temperaturas mais altas e chuvas escassas. Esses eventos são relacionados pelos mesmos com a redução das áreas florestais. Conforme Silva e Freire (2010) e Brasil e Brasil-Guimarães (2018), a vegetação da Caatinga vem sofrendo sucessivas perdas de área nativa e grande parte de seus recursos florais estão desaparecendo de forma significativa ou permanentemente.

De acordo com Silverwood-Cope et al. (2011), as mudanças do clima no passado decorreram de fenômenos naturais. Entretanto, nos últimos 50 anos, a maior parte das mudanças climáticas atuais e futuras são decorrentes das atividades humanas. Segundo o Painel Intergovernamental sobre Mudança do Clima (IPCC 2007) e Angelotti et al. (2015), no Brasil, a região semiárida será uma das mais afetadas pelas mudanças climáticas globais.

Marengo (2008) considerou e avaliou diversas situações de vulnerabilidade associadas as mudanças climáticas no semiárido nordestino, como a disponibilidade de água, a segurança alimentar regional e a saúde da população. Além disso, o Painel Brasileiro de Mudanças Climáticas (PBMC 2014) destacou que os cenários de clima apontariam, nas próximas décadas, para aumento de temperatura do ar e diminuição de chuvas na região. Os agentes mais vulneráveis seriam aqueles com menos recursos e menor capacidade para se adaptar a transformações, tais como trabalhadores de baixa renda, principalmente na agricultura de subsistência.

Para o território brasileiro, ainda não existem dados substanciais de que as mudanças climáticas constituem ameaça direta às colônias de Apis mellifera, importante espécie polinizadora. Apesar disso, os dados iniciais apontam que algumas espécies de pragas, predadores ou competidores exóticos poderão ser beneficiados pelas mudanças climáticas, expandindo a sua área de distribuição no Brasil (Wolowski et al. 2019). Um desdobramento preocupante das mudanças do clima, portanto, é a perda de biodiversidade, em especial, o declínio de polinizadores (Garófalo 2013; Azevedo 2016; Wolowski 2019). Essas espécies são responsáveis por um serviço ambiental essencial para inúmeras culturas vegetais das quais se servem os humanos e outros animais. $\mathrm{O}$ declínio desses polinizadores afetaria toda a atividade apícola de uma região ou do país. 
No atual e futuro contexto de mudanças climáticas, é de suma importância o desenvolvimento de formas de produção menos agressivas, como a agricultura familiar tradicional, a produção orgânica e a agroecologia (Azevedo 2016). Nesse sentido, a apicultura, importante atividade econômica, possui relevância conhecida para a manutenção do bom funcionamento dos ecossistemas silvestres e agrícolas (Freitas e Pinheiro 2012). Essa atividade, portanto, deve ser valorizada e incentivada, de forma contínua, pois abelhas não só proporcionam um componente necessário à reprodução para muitas espécies vegetais, mas, também, um aumento da variabilidade genética, da viabilidade das sementes e incremento na produção de sementes e frutos (Bacaxixi et al. 2011, Garófalo 2013).

Práticas agrícolas ambientalmente viáveis e apicultura, em especial na Caatinga, devem favorecer a interação de apicultores com a fauna (abelhas) e a flora (espécies vegetais apícolas), fator essencial para assegurar a viabilidade econômica da atividade na região (Aleixo et al. 2014; Costa et al. 2018). Essa dinâmica gera uma relação de pertencimento e preservação da flora local. De acordo com Hanazaki (2002), o conhecimento popular sobre o uso das espécies vegetais nativas pode contribuir para a conservação, no que diz respeito à adoção de práticas de manejo, além de contribuir para o resgate e preservação da cultura popular.

\section{Conclusões}

A área do semiárido Potiguar estudada apresenta uma grande diversidade de espécies vegetais com diferentes usos em potencial, com destaque para o medicinal, sendo as formas de preparo mais frequentes, o chá, lambedor e in natura, respectivamente.

Além do etnoconhecimento sobre a diversidade de usos das plantas da região, os apicultores de Marcelino Vieira - RN detêm saber empírico notável, bem como percebem e refletem sobre questões relacionadas as ações antrópicas que impactam a vegetação local e as alterações ambientais e atuais decorrentes do agravamento das mudanças climáticas. Os apicultores atuam como agentes promotores da conservação das espécies nativas do município e os saberes tradicionais e etnobotânicos carecem de maior valorização, culminando, assim, com a utilização racional e proteção da biodiversidade da Caatinga.

Nesse sentido, percebe-se que é de suma importância que sejam traçadas estratégias de conservação e reflorestamento de espaços degradados em Marcelino Vieira, visando o avanço do desenvolvimento econômico do referido município e a manutenção dos recursos vegetais e saberes associadas a comunidade, contribuindo para a manutenção do clima, economia local e equilíbrio ambiental.

\section{Agradecimentos}

O presente trabalho foi realizado com apoio da Coordenação de Aperfeiçoamento de Pessoal de Nível Superior - Brasil (CAPES) - Código de Financiamento 001, da Fundação de Amparo a Ciência e Tecnologia de PE (FACEPE) e do Conselho Nacional de Desenvolvimento Científico e Tecnológico $(\mathrm{CNPq})$ por meio de bolsa de produtividade a MIBL.

Participação dos autores: todos os autores contribuíram significativamente para a confecção do manuscrito. CPC realizou as expedições de campo, entrevistas, compilação dos dados, redação e correção do manuscrito; RTMR - auxiliou na compilação dos dados, discussão dos resultados, redação, leitura, revisão, normatização e submissão do manuscrito; 
MIBL - supervisionou as etapas de campo e análises de dados, contribuiu na discussão dos resultados, redação, leitura, revisão e correção do manuscrito.

Aprovação ética ou licenças de pesquisa: a pesquisa foi submetida a apreciação do Comitê de Ética em Pesquisa da Universidade Federal do Ceará (UFC) sob número CAAE: 89184818.6.0000.5054 e aprovada sob parecer consubstanciado $n^{\circ}$ 2.698.897. Cadastro no Sistema Nacional de Gestão do Patrimônio Genético e do Conhecimento Tradicional Associado (SisGen): A1BC7DE. Autorização do Sistema de Autorização e Informação em Biodiversidade (SISBIO): 64026-1.

Disponibilidade dos dados: os dados estão disponibilizados nas tabelas apresentadas no manuscrito.

Fomento: Coordenação de Aperfeiçoamento de Pessoal de Nível Superior - Brasil (CAPES) - Código de Financiamento 001; CNPq (Processo 308685/2020-2); FACEPE (BFP-0160-2.03/20).

Conflito de Interesses: os autores declaram não existir conflito de interesses.

\section{Referências}

Albuquerque UP, Lucena RFP, Cunha LVFC. 2010. Métodos e técnicas na pesquisa etnobiológica e etnoecológica, 1 ed., Recife: NUPPEA, 559 p.

Aleixo D L, Araújo WL, Angra RS, Maracajá PB, Sousa MJO. 2014. Mapeamento da flora apícola arbórea das regiões pólos do estado do Piauí. Revista Verde, 9(4):262-270.

Almeida VS. 2011. Uso, manejo e estrutura da vegetação da caatinga por duas comunidades quilombolas do município de Jeremoabo, Bahia, Brasil. Universidade Estadual de Feira de Santana. Programa de Pós-graduação em Botânica. Tese de Doutorado, 161p.

ANVISA. Agência Nacional de Vigilância Sanitária. 2017. Lista DCB Plantas Medicinais atualizada em dezembro 2017 (Versão 1.0).

Amorim LDM, Sousa LOFS, Oliveira FFMO, Camacho RGVC, Melo JIM. 2016. Fabaceae na Floresta Nacional (FLONA) de Assú, semiárido potiguar, nordeste do Brasil. Rodriguésia, 67(1):105-123. https://doi.org/10.1590/21757860201667108 .

Angelotti F, Signor DS, Giongo V. 2015. Mudanças climáticas no semiárido brasileiro: experiências e oportunidades para o desenvolvimento. Revista Brasileira de Geografia Física, 4(8):484-495. DOI: https://doi.org/10.26848/rbgf. v8.0.p484-495.

Azevedo AR. 2016. Produção de alimentos e mudanças climáticas: a importância da agroecologia e da apicultura como alternativas para mitigação de impactos. Universidade Federal Rural do Rio de Janeiro. Programa de Pós-graduação em Práticas em Desenvolvimento Sustentável. Dissertação de Mestrado, 86p.

Bacaxixi P, Bueno CEMS, Ricardo HÁ, Epiphanio PD, Silva DP, Barros BMC, Silva TF, Bosquê GG, Lima FCC. 2011. A importância da apicultura no Brasil. Revista Científica Eletrônica de Agronomia, 10(20):1-6.

Baracuhy JGV, Furtado DA, Francisco PRM, Lima JLSL, Pereira JPGP. 2016. Plantas medicinais de uso comum no Nordeste do Brasil, Campina Grande, PB: UDUFCG. 82 p.

Beltrão BA et al. (Orgs.). 2005. Projeto cadastro de fontes de abastecimento por água subterrânea, estado do Rio Grande do Norte: relatório diagnóstico do município de Marcelino Vieira. Recife: CPRM. Disponível em: http://rigeo.cprm.gov. br/jspui/handle/doc/17022. Acesso em: 12 jan. 2021.

Bernard HR. 2017. Research methods in anthropology: qualitative and quantitative approaches. 6th edition. London: Rowman \& Littlefield Publishers, 732 p.

Bessa MAP, Medeiros JF. 2011. Levantamento Floristico e Fitossociológico em fragmentos de Caatinga no município de Taboleiro Grande - RN. Geotemas, 1(2):69-83. DOI: https://doi.org/10.33237/geotemas.v1i2.142. 
BFG. Brazil Flora Group. 2015. Growing knowledge: an overview of Seed Plant diversity in Brazil. Rodriguésia, 66:10851113. DOI: https://doi.org/10.1590/2175-7860201566411.

Blank DMP. 2015. O Contexto das mudanças climáticas e as suas vítimas. Mercator, 14(2):157-172. https://doi. org/10.4215/RM2015.1402.0010.

Brasil. 2016. Resolução n 510, de 7 de abril de 2016, do Conselho Nacional de Saúde. Ministério da Saúde, Diário Oficial da União.

Brasil D De F, Brasil-Guimarães M. De O. 2018. Principais recursos florais para as abelhas da Caatinga. Revista Scientia Agraria Paranaensis, 17(2):149-156.

Cabral GAL, Maciel JR. 2011. Levantamento Etnobotânico da coleção de plantas medicinais do Jardim Botânico do Recife, PE. Natureza on line, 9(3):146-151.

Castanho ADA, Coe M, Andrade EM, Walker W, Baccini A, Campos DA, Farina M. 2020. A close look at above ground biomass of a large and heterogeneous Seasonally Dry Tropical Forest-Caatinga in Northeast of Brazil. Anais da Academia Brasileira de Ciências, 92(1):e20190282. DOI: https://dx.doi.org/10.1590/0001-3765202020190282.

CLIMATE-DATA. Clima Marcelino Vieira: Temperatura, Tempo e Dados Metereológicos. 2021.

Costa JMO, Pinto CWC, Bezerra CS, Brito LHR, Nóbrega JE. 2018. Flora apícola em área de manejo da Caatinga em município de Prata, PB. Revista Tecnologia \& Ciência Agropecuária, 12(5):1-6.

Dantas CG, Nunes TLGM, Nunes TLGM, Gomes MZ, Gramacho KP. 2013. Apitoxina: Coleta, Composição Química, Propriedades Biológicas e Atividades Terapêuticas. Revista Ibero-Americana de Ciências Ambientais, 4(2):127-150. DOI: https://doi.org/10.6008/ESS2179-6858.2013.002.0009.

Da Silva CI, Nascimetno, JEM, Girão EG, Radaeski JN, Queiroz EP, Câmara CP, Nascimento ERM, Machado JS, Freitas BM, Barth OM, Raulino DS, Maia CWCP. 2020. Catálogo polínico, inventário florístico e produção de mel em Marcelino Vieira, Rio Grande do Norte, Brasil. Fortaleza: Embrapa Agroindústria Tropical, 114 p.

De Sá CG, De Barros SO, Gomes AP, Silva Filho FA, Teixeira KSS. 2015. Plantas Medicinais Usadas na Região Nordeste: Revisão integrativa. Revista Interdisciplinar de Ciências Médicas, 1:1-22. DOI: https://doi.org/10.31692/ ICOINTERPDVS.2019.0011.

Fernandes MF, Cardoso D, De Queiroz LP. 2020. An updated plant checklist of the Brazilian Caatinga seasonally dry forests and woodlands reveals high species richness and endemism. Journal of Arid Environments, 174:104079174. DOI: https://doi.org/10.1016/j.jaridenv.2019.104079.

Flora do Brasil 2020 em construção. Jardim Botânico do Rio de Janeiro.

Freitas AVL, Coelho M De FB, Maia SSS, Azevedo RAB De. 2012. Plantas medicinais: um estudo etnobotânico nos quintais do Sítio Cruz, São Miguel, Rio Grande do Norte, Brasil. Revista Brasileira de Biociências, 10:48-59.

Freitas BM e Pinheiro JN. 2012. Polinizadores e pesticidas: princípios e manejo para os agroecossistemas brasileiros. Brasília: MMA. 112 p.

Garófalo CA. 2013. As abelhas e a sustentabilidade dos serviços de polinização. Ribeirão Preto: USP.

Giannini TC, Costa WF, Cordeiro GD, Imperatiz-Fonseca VL, Saraiva AM. 2017. Efeito das mudanças climáticas sobre os polinizadores de algumas culturas agrícolas no Brasil. Revista Mensagem Doce, 143.

Giulietti AM et al. 2003. Diagnóstico da vegetação nativa do bioma caatinga. In: Silva JMC, Tabarelli M, Fonseca MT, Lins LV (Org.). Biodiversidade da Caatinga: áreas e ações prioritárias para a conservação. Brasília, DF: Ministério do Meio Ambiente/Universidade Federal de Pernambuco, p. 47-90. 
Hanazaki N. 2002. Conhecimento caiçara para o manejo de recursos naturais. In: Anais do IV Simpósio Brasileiro de Etnobiologia e Etnoecologia, Recife, p. 17-25.

IBGE. Instituto Brasileiro de Geografia e Estatística. 2012. Manual técnico da vegetação brasileira. 2 ed., Rio de Janeiro: IBGE, $272 \mathrm{p}$.

IBGE. Instituto Brasileiro de Geografia e Estatística. 2016. Brasil em síntese: Rio Grande do Norte, Marcelino Vieira Panorama. Cidades.

IDEMA. Instituto de Desenvolvimento Sustentável e Meio Ambiente do Rio Grande do Norte. 2008. Perfil do seu Município: Marcelino Vieira. 10:1-22.

IFAG. Inventário Florístico Apícola Georreferenciado. 2017. Inventário Florístico Apícola (Participativo) e Georreferenciado no Município de Marcelino Vieira, Alto Oeste Potiguar - RN. Relatório Técnico. Natal, EMBRAPA.

IPCC. Intergovernmental Panel On Climate Change. 2007. Mudança do clima: impactos, adaptação e vulnerabilidade contribuição do Grupo de Trabalho II ao Quarto Relatório de Avaliação do Painel Intergovernamental sobre Mudança do Clima. Genebra: IPCC. 104 p.

Loiola MIB, Paterno GB De C, Diniz JA, Calado JF, Oliveira ACP De. 2010. Leguminosas e seu potencial de uso em comunidades rurais de São Miguel do Gostoso - RN. Revista Caatinga, 23(3):59-70.

Lucena RFP, Soares TC, Vasconcelos-Neto CFA, Carvalho TKN, Lucena CM, Alves RRN. 2012. Uso de recursos vegetais da caatinga em uma comunidade rural no Curimataú Paraibano (Nordeste do Brasil). Polibotânica, 34:217-238.

Marengo JÁ, Nobre CA, Tomasella J, Oyama MD, Oliveira GS, Oliveira R, Camargo H, Alves LM, Briwnm IF. 2008. The drought of Amazonia in 2005. Journal of Climate, 21:495-516. DOI: https://doi.org/10.1175/2007JCLI1600.1.

Marodin SM, Batista LM. 2002. Plantas medicinais do Município de Dom Pedro de Alcântara, estado do Rio Grande do Sul, Brasil: espécies, famílias e usos em três grupos da população humana. Revista Brasileira de Plantas Medicinais, 5:1-9.

Martin GJ. 1995. Ethnobotany: a conservation manual. London: Chapman \& Hall, 268 p.

Minayo MC de S. 2013. Pesquisa Social: Teoria, método e criatividade. Petrópolis: Editora Vozes. 111 p.

Moreira DR. 2012. Apiterapia no Tratamento de Patologias. Revista F@pciência, 9(4):21-29.

Mosca VP, Loiola MIB. 2009. Uso popular de plantas medicinais no Rio Grande do Norte, Nordeste do Brasil. Revista Caatinga, 22(4):225-234.

OMS. Organização Mundial De Saúde. 2017. Classificação estatística internacional de doenças e problemas relacionados à saúde. São Paulo: Editora da Universidade de São Paulo. 1200 p.

PBMC. Painel Brasileiro De Mudanças Climáticas. 2014. Impactos, vulnerabilidades e adaptação às mudanças climáticas. Contribuição do Grupo de Trabalho 2 do Painel Brasileiro de Mudanças Climáticas ao Primeiro Relatório da Avaliação Nacional sobre Mudanças Climáticas. Rio de Janeiro: COPPE/UFRJ.

Phillips O, Gentry AH. 1993. The useful plants of Tambopata, Peru: I. Statistic al hypotheses tests with a new quantitative technique. Economic Botany, 47(1):15-32. DOI: https://doi.org/10.1007/BF02862203.

Queiroz LP. 2009. Leguminosas da Caatinga. Feira de Santana: UEFS, 460 p.

Ribeiro DA, Macêdo DG, Oliveira LGS, Saraiva ME, Oliveira SF, Souza MMA, Menezes IRA. 2014. Potencial terapêutico e uso de plantas medicinais em uma área de Caatinga no estado do Ceará, nordeste do Brasil. Revista Brasileira de Plantas Medicinais, 16(4):912-930. DOI: https://doi.org/10.1590/1983-084X/13_059. 
Rito KF, Arroyo-Rodríguez V, Queiroz RT, Leal IR, Tabarelli M. 2017. Precipitation mediates the effect of human disturbance on the Brazilian Caatinga vegetation. Journal of Ecology, 105(3):828-838. DOI: https://doi.org/10.1111/13652745.12712.

Roque AA, Rocha RM, Loiola MIB. 2010. Uso e diversidade de plantas medicinais da Caatinga na comunidade rural de Laginhas, município de Caicó, Rio Grande do Norte (nordeste do Brasil). Revista Brasileira de Plantas Medicinais, 12(1):31-42. DOI: https://doi.org/10.1590/S1516-05722010000100006.

Roque AA, Loiola MIB. 2013. Potencial de uso dos recursos vegetais em uma comunidade rural no semiárido potiguar. Revista Caatinga, 26(4):88-98.

Rovedder APM, Piazza EM, Thomas PA, Felker RM, Hummel RB, Farias JA. 2016. Potential medicinal use of forest species of the Deciduous Seasonal Forest from Atlantic Forest Biome, South Brazil. Brazilian Archives of Biology and Technology, 59:e16150329. DOI: https://doi.org/10.1590/1678-4324-2016150329.

Schirmer LR. 1985. Abelhas Ecológicas. São Paulo: Editora Nobel.

SFB. Serviço Florestal Brasileiro. 2018. Inventário Florestal Nacional: principais resultados - Rio Grande do Norte (Série Relatórios Técnicos - IFN). Brasília: MMA.

Silva VG. 2000. O antropólogo e sua magia. São Paulo: Edusp, 194 p.

Silva TS, Freire EMX. 2010. Abordagem etnobotânica sobre plantas medicinais citadas por populações do entorno de uma unidade de conservação da caatinga do Rio Grande do Norte, Brasil. Revista Brasileira de Plantas Medicinais, 12(4):427-435. DOI: https://doi.org/10.1590/S1516-05722010000400005.

Silva CG, Marinho MGV, Lucena MFA, Costa JGM. 2015. Levantamento etnobotânico de plantas medicinais em área de Caatinga na comunidade do Sítio Nazaré, município de Milagres, Ceará, Brasil. Revista Brasileira de Plantas Medicinais, 17(1):133-142. DOI: https://doi.org/10.1590/1983-084X/12_055.

Silverwood-Cope K De O, Villarroel LCL, Serkeis APM, Kamber A. 2011. Mudanças Climáticas. Brasília: MMA, 2011. $32 \mathrm{p}$.

Spradley JP, McCurdy DW. 1972. The cultural experience: ethnographyin complex society. USA: Science Research Associates, 246 p.

Weller SC, Romney KA. 1998. Systematic data collection. California: Sage, Newbury Park, 96 p.

Wolowski M, Agostini K, Rech AR, Varassin IG, Maués M, Freitas L, Carneiro LT, Bueno R De O, Consolaro H, Carvalheiro L, Saraiva AM, Silva CI Da. (Orgs.), Relatório temático sobre polinização, polinizadores e produção de alimentos no Brasil, São Carlos: Editora Cubo, 2019. 